\title{
Sexual knowledge and practice of adolescent learners in a rural South African school
}

\author{
Karien Mostert ${ }^{1}$, Khethiwe M Sethole ${ }^{3}$, Oumiki Khumisi ${ }^{2}$, Dorrica Peu², Julius Thambura ${ }^{3}$, \\ Roinah N Ngunyulu ${ }^{2}$, Mavis F Mulaudzi²
}

\section{Department of Physiotherapy}

2. Department of Nursing Science

3. Department of Radiography

1,2,3. School of Health Care Sciences, Faculty of Health Care, University of Pretoria, P.O. Box 667, Pretoria, South Africa, 0001

\section{Emails:}

Khethiwe M Sethole- margaret.sethole@up.ac.za; Oumiki Khumisi- oumiki.khumisi@up.ac.za; Dorrica Peudoriccah.peu@up.ac.za; Julius Thambura- julius.thambura@up.ac.za; Roinah N Ngunyulu-rnngunyulu@uj.ac.za; Mavis F Mulaudzi- mavis.mulaudzi@up.ac.za

\begin{abstract}
Background: Premature sexual activity has become a norm in South African society, often resulting in teenage pregnancy and sexually transmitted diseases (STD). Occurrence of premature sexual activity is related to insufficient education, gender inequalities, household poverty and place of residence. The Stepping Stones project uses a 10-session programme to educate learners about relationships, HIV-prevention and teenage pregnancy. The purpose was to measure and describe learners' sexual knowledge and activities in a rural technical secondary school in North-west Province, South Africa.

Methods: A cross-sectional survey. Questionnaires were distributed to learners in grade 8 to 12. Descriptive statistics was used in analysis.

Results: Seventy-nine questionnaires were analysed. Despite a young sample, $26.6 \%$ were sexually active and $24.1 \%$ engaged in sexual activity. The mean age for first-time sexual intercourse was $15.2 \pm 2.3$ years. The use of contraceptives was low $(41.2 \%)$ and participants reported difficulty in talking to partners about condom use $(54.8 \%)$. Almost half (45.5\%) of the participants had never heard of STDs. Participants expressed a need to use social media as a sex education tool (12.3\%). The primary source of information was from school-based programmes (58.0\%).

Conclusion: Findings point to unsafe sexual practice of learners at a school in rural South Africa, even from an early age. This concern is accompanied by the occurrence of low levels of sexually-related knowledge. The learners would benefit from continued implementation of the Stepping Stones programme. Implementation could be improved by incorporating social media and emphasising gender equality and negotiation skills in sexually vulnerable situations.
\end{abstract}

Keywords: Sexual knowledge, adolescent learners, South Africa.

DOI: https://dx.doi.org/10.4314/ahs.v20i1.6

Cite as: Mostert K, Sethole KM, Khumisi O, Peu D, Thambura J, Ngunyulu RN, et al. Sexual knowledge and practice of adolescent learners in a rural South African school. Afri Health Sci. 2020;20(1):28-38. https:// dx.doi.org/10.4314/abs.v20i1.6

\section{Introduction}

Adolescence is a difficult and critical time of experimen-

\section{Corresponding author: \\ Karien Mostert, Postal Address: School of Health Care Sciences, Faculty of Health Care, University of Pretoria, P.O.Box 667, Pretoria, 0001 \\ Cell Phone: +27823127159 \\ Email address: karien.mostert@up.ac.za}

tation, new experiences and vulnerability. Experimentation may include drugs, reflecting on sexual orientation and also sexual experiences. In South Africa, $42 \%$ of females and $63 \%$ of males are sexually active by the age of $18^{1}$. Premature sexual activity has far reaching effects on teenage pregnancy and sexually transmitted diseases. The National Strategic Plan for HIV, TB and sexually transmitted infections (STIs) reports the rates of teenage pregnancy in South Africa is 39\% in 15 to 19 -yearold girls ${ }^{2}$. The 2014 General Household Survey reported a teenage pregnancy rate of $5.6 \%$ for females aged be- 
tween 14 and $19^{3}$. These teenage pregnancies contributed to $13.2 \%$ of registered live births in South Africa ${ }^{4}$. In South Africa, adolescent pregnancy is linked to permissive sexual behaviour ${ }^{5}$. Globally, a large proportion (70\%) of HIV infected people, of which more than a half is women, and two-thirds of new HIV infections occurred in sub-Saharan Africa ${ }^{6}$. HIV prevention is therefore concomitant with the prevention of teenage pregnancy in South Africa.

High rates of HIV infection and teenage pregnancies in South Africa can be related to early sexual behaviour. Early sexual debut has been linked to multiple risk factors, including poor education, multiple lifetime partners and substance abuse ${ }^{7}$. A lack of knowledge surrounding HIV prevention, transmission and treatment may be responsible for the spread of the disease ${ }^{8}$. A large proportion of people living in high risk areas believe themselves not to be at risk, indicating a lack of understanding of HIV transmission and discrepancies in risk perception due to fluid relationship patterns". Various interventions, such as HIV counselling and testing (HCT) and the LoveLife education programme have been proposed at global, national and school level but they have been ineffective due to stigmatisation and the prospect of a positive HIV outcome (Department of Health and Department of Basic Education, 2012). Many adolescents, who remain untested, are not receiving counselling and are engaging in risky behaviour that cause transmission of $\mathrm{HIV}^{10}$. Gender power imbalances (associated with significantly older partners in particular), early sexual debut, barriers to contraceptive use, misinformation on sexual health matters and lack of parental support at home also increase the risk of teenage pregnancies ${ }^{11}$.

Behavioural intervention programmes have been successful in delaying sexual debut and increased condom use among sexually active South African youth ${ }^{12}$. Irrespective of the existing preventive and promotive health services provided, the majority of adolescents still lack knowledge of sexual health practices. Existing programmes have been aimed at improving health-related knowledge and focussed on preventing diseases. Despite an increase in knowledge, South African youth are still prone to risky behaviour perpetuated by societal norms ${ }^{5}$. Stepping Stones is a promising school-based programme seeking to achieve the prevention of HIV and teenage pregnan- cy through promoting gender equality and sexual health. Stepping Stones has been implemented in eight countries and has improved condom use, communication of HIV information and gender equality ${ }^{13}$. Careful consideration should be given to local risk factors and context of the specific community to determine the optimal intervention (2010). Long-term efficacy of prevention interventions can only be assessed if a baseline exists for future comparisons. The aim of this article is to report on the sexual knowledge and activity of learners at a rural school before the implementation of the Stepping Stones project in this particular community.

\section{Methods}

Promoting sexual health is part of the health-promoting schools programme of the School of Health Care Sciences, University of Pretoria. Four schools were part of this initiative. This article reports on the situation at a secondary school, situated in a rural resource poor community in North-west Province, South Africa.

A quantitative cross-sectional study was carried out. The relevant coordinating teachers introduced the data collector to each of the classes. All learners from both genders were invited to participate. Appointments were made prior to data collection. The data collector (a trained research assistant with a Master's degree) informed the learners about the study. Questionnaires were completed during class time offered by the school. All learners from both genders aged 12 to 18 that consented to participate were invited to the study, as this age group of the learners involved is characterised by sexual debut and vulnerability to STDs

A literature-based questionnaire was developed and input from stakeholders were obtained. Stakeholders included teachers from the school, learners, representatives from non-governmental organisations in the community involved in promoting sexual health and university lecturers. New items were added and the wording of existing items was improved to be culturally sensitive. The questionnaire consisted of sections $\mathrm{A}$ to $\mathrm{F}$ with a total of 42 questions. The questions were structured in multiple-choice format that explored the following areas (1) Section A: Demographic information, (2) Sections B and C: Current sexual practice, and (3) Sections D, E and F: Knowledge about STD and pregnancy. 
A research assistant distributed the questionnaires. She was available during the completion of the questionnaire to clarify anything that participants were not certain about. The questionnaires were in English, but the assistant could explain in the participants' mother tongue, se'Tswana. Data was captured in spreadsheets. Descriptive statistics was then used for data analysis in Microsoft Excel (2007).

Clearance for the study was received from the Ethics Committee, Faculty of Health Sciences, University of Pretoria (Reference no. 464/2014). The local Department of Education and the principal of the school gave permission to conduct the study. Written informed consent was obtained from parents for participation by learners. The aim of the study and their rights were explained to learners before the questionnaire was distributed. Completion of the instrument implied assent for participa- tion. No remuneration or other incentives was offered or provided.

\section{Results}

The results are presented with respect to three categories: demographic characteristics, current sexual practice and knowledge of sexual health.

\section{Demographic information}

The study had 79 participants (of 125) of whom 62 were females and 16 males (Table 1$)$. Forty $(50.6 \%)$ of the participants stayed outside of Makanpanstad. Most participants lived with both parents $(45.6 \%)$ or solely with the mother $(36.7 \%)$. The majority of parents were employed $(81 \%)$. Christianity was the religion of choice for the majority $(98.7 \%)$. Grades 8 to 11 (mean age $=13$ ) were represented during the study with grade 8 having the largest representation (46.8\%) followed by Grade 11 (25.3\%) and Grade 10 (15.2\%).

Table 1. Demographic profile

\begin{tabular}{|c|c|c|}
\hline Characteristic & $\begin{array}{l}\text { Frequency } \\
(n=79)\end{array}$ & $\begin{array}{l}\text { Percentage } \\
(\%)\end{array}$ \\
\hline \multicolumn{3}{|l|}{ Gender } \\
\hline Females & 62 & 78.5 \\
\hline Males & 16 & 20.3 \\
\hline \multicolumn{3}{|l|}{ Residence } \\
\hline Makapanstad & 39 & 49.4 \\
\hline Other & 40 & 50.6 \\
\hline \multicolumn{3}{|l|}{ Living arrangements } \\
\hline Mother & 29 & 36.7 \\
\hline Father & 4 & 5.1 \\
\hline Both parents & 36 & 45.6 \\
\hline Relatives & 9 & 11.4 \\
\hline \multicolumn{3}{|c|}{ Employment status of parents } \\
\hline \multirow{2}{*}{$\begin{array}{l}\text { Employed } \\
\text { Not employed }\end{array}$} & 64 & 81.0 \\
\hline & 15 & 19.0 \\
\hline \multicolumn{3}{|l|}{ Religion } \\
\hline \multirow{2}{*}{$\begin{array}{l}\text { Christian } \\
\text { Hindu }\end{array}$} & 78 & 98.7 \\
\hline & 0 & 0.0 \\
\hline \multicolumn{3}{|l|}{ /Muslim } \\
\hline Other & 1 & 1.3 \\
\hline \multicolumn{3}{|l|}{ School Grade } \\
\hline Grade 8 & 37 & 46.8 \\
\hline Grade 9 & 10 & 12.7 \\
\hline Grade 10 & 12 & 15.2 \\
\hline Grade 11 & 20 & 25.3 \\
\hline
\end{tabular}




\section{Current sexual practice}

\section{Pregnancies}

Two previous pregnancies were reported, but none of the participants had children (Table 2).

\section{Age at sexual debut and sexual activity}

The mean age for first sexual intercourse was 15.2 years. The youngest age at sexual debut was 11 years old and the oldest was 17 years old. However, only 21 (26.6\%) reported being sexually active at the time of the study. Despite not having sex, $24.1 \%$ had an introduction to sexual activity by touching the genitals of the opposite sex. Of those who were sexually active, vaginal sex was the most common type of sexual activity $(85.7 \%)$ with a partner that was of a mean age of 17.7 years. Most of the participants $(n=38,48.1 \%)$ did not have a sex partner at the time of the study or either had a single partner $(n=33,41.8 \%)$ with the minority reporting more than one partner $(n=8$, 10.1\%). Probably when participants answered the first question about having sex, they were considering sexual activity with penetration. The answer about the number of sexual partners probably relate to partners with which different types of sexual activity were practiced.

Table 2. Distribution of current sexual practice $(n=79)$

\begin{tabular}{|c|c|c|c|c|c|}
\hline Practice & Count & $\%$ & Practice & Count & $\%$ \\
\hline \multicolumn{3}{|l|}{ Sexually active } & \multicolumn{3}{|c|}{ Speaking about condom use } \\
\hline Yes & 21 & 26.6 & Easy & 19 & 45.2 \\
\hline No & 58 & 73.4 & Difficult & 23 & 54.8 \\
\hline \multicolumn{3}{|c|}{ Sexual activity by age* } & \multicolumn{3}{|c|}{ How often use condoms? } \\
\hline 13 & 0 & 0 & Always & 21 & 50.0 \\
\hline 14 & 1 & 4.8 & Often & 0 & 0.0 \\
\hline 15 & 1 & 4.8 & Sometimes & 6 & 14.3 \\
\hline 16 & 8 & 38.1 & Rarely & 2 & 4.8 \\
\hline 17 & 7 & 33.3 & Never & 13 & 31.0 \\
\hline 18 & 4 & 19.0 & None & 0 & 0.0 \\
\hline \multicolumn{3}{|l|}{ Type of sex } & \multicolumn{3}{|l|}{ Regret having sex? } \\
\hline Vaginal sex & 18 & 42.9 & Yes & 14 & 31.1 \\
\hline Touching genital & 14 & 33.3 & No & 38 & 68.9 \\
\hline Oral sex & 6 & 14.3 & \multicolumn{3}{|c|}{ Reasons for sexual activity } \\
\hline Anal sex & 1 & 2.4 & $\begin{array}{l}\text { Felt I was the } \\
\text { right age }\end{array}$ & 2 & 5.3 \\
\hline Other & 3 & 7.1 & $\begin{array}{l}\text { Wanted to lose } \\
\text { my virginity }\end{array}$ & 2 & 5.3 \\
\hline \multicolumn{3}{|c|}{ No of current sex partners } & $\begin{array}{l}\text { Friends all doing } \\
\text { it }\end{array}$ & 1 & 2.6 \\
\hline One & 33 & 41.8 & I was in love & 22 & 57.9 \\
\hline More than 1 & 8 & 10.1 & $\begin{array}{l}\text { Natural flow of } \\
\text { relationship }\end{array}$ & 3 & 7.9 \\
\hline None & 38 & 48.1 & Curious & 1 & 2.6 \\
\hline \multicolumn{3}{|c|}{ Contraceptive use } & \multicolumn{3}{|c|}{ Choice of contraceptives } \\
\hline Yes & 21 & Pill & 1 & 1.3 & \\
\hline \multirow[t]{5}{*}{ No } & 30 & Injectable & 1 & 1.3 & \\
\hline & & & Implants & 4 & 5.1 \\
\hline & & Condom & 16 & 20.3 & \\
\hline & & & Intra-uterine & 2 & 2.5 \\
\hline & & & None & 55 & 69.6 \\
\hline
\end{tabular}

*More than one option could be selected 


\section{Contraceptive use}

Contraceptive use was low $(41.2 \%)$, probably due to most of participants not being sexually active. Not all of the sexually active participants used a condom (61.9\%), with $21(42.9 \%)$ reporting that they 'sometimes, rarely or never' use a condom. Intra-uterine implants were the second most popular means of contraception $(3.8 \%)$. Of the sexually active participants, $14.3 \%$ reported not using any contraception. Condom use was a difficult topic for participants to talk about with their partners $(n=23,54.8 \%)$.

\section{Perceptions and relationships}

Most participants did not regret having sex $(n=38,69.0 \%)$ and cited being in love $(57.9 \%)$ and the natural flow of a relationship $(7.9 \%)$ as being the main reasons for sexual activity. There were two cases of reported sexual assault, where the reasons for sex were stated as 'physically forced'. Other reasons for sex included: sex felt age-appropriate, being under the influence of alcohol/drugs, simply wanted to lose virginity and got carried away $(5.3 \%)$. The learners reported that being acquainted with a partner for a few years was the most appropriate criterion for having sex $(35.7 \%)$, followed by a few months $(31.0 \%)$. Conflicting opinions were reported as to appropriate relationship patterns with votes tied between being in a committed relationship or having just met (14.3\%).

\section{Knowledge of sexual health \\ Source of information}

Most participants were introduced to puberty and sex-education at 11.2 years. Participants reported their primary source of information as teachers $(58.0 \%)$ and friends $(12.3 \%)$ (Table 3). Most of the participants would have preferred gaining knowledge from either a mother $(50 \%)$ or sister $(18.8 \%)$. Many participants did receive information from parents but were not satisfied with the information supplied $(38.0 \%)$. Television $(42.2 \%)$, magazines or books $(28.9 \%)$ and the internet or social media (9.6\%) were the most important other sources of knowledge. Participants felt that magazines or books could be better utilised as teaching aid in future $(32.1 \%)$, as well as social media $(12.3 \%)$.

Table 3. Sources of information about sexual practice

\begin{tabular}{|c|c|c|c|c|}
\hline \multicolumn{3}{|c|}{ Sources of knowledge } & \multicolumn{2}{|l|}{ Preferred sources } \\
\hline Variable & $\begin{array}{l}\text { Frequency } \\
(n=79)\end{array}$ & $\begin{array}{l}\text { Percentage } \\
(\%)\end{array}$ & Variable & $\begin{array}{l}\text { Frequency } \\
(n=79)\end{array}$ \\
\hline Mother & 8 & 9.9 & Mother & 40 \\
\hline Father & 0 & 0.0 & Father & 4 \\
\hline Grandparents & 1 & 1.2 & Grandparents & 2 \\
\hline Sibling & 11 & 13.9 & Brother & 2 \\
\hline Friend & 10 & 12.3 & Sister & 15 \\
\hline Teacher & 47 & 58.0 & Friend & 2 \\
\hline \multirow[t]{2}{*}{ Other } & 4 & 4.9 & Teacher & 12 \\
\hline & & & Other & 3 \\
\hline \multicolumn{2}{|l|}{ Which resources } & & \multicolumn{2}{|l|}{ Preferred source } \\
\hline Television & 35 & 42.2 & Television & 14 \\
\hline Magazines/Books & 24 & 28.9 & Magazines/Books & 26 \\
\hline Internet & 8 & 9.6 & Internet & 6 \\
\hline Leaflets & 0 & 0.0 & Leaflets & 1 \\
\hline Films/videos & 1 & 1.2 & Films/videos & 7 \\
\hline Radio & 1 & 1.2 & Radio & 3 \\
\hline Posters & 1 & 1.2 & Posters & 5 \\
\hline Social media & 8 & 9.6 & Social media & 10 \\
\hline Other & 5 & 6.0 & Other & 9 \\
\hline \multicolumn{5}{|c|}{ Satisfied with information from parents } \\
\hline Yes & 43 & 54.4 & & \\
\hline No & 30 & 38.0 & & \\
\hline None & 6 & 7.6 & & \\
\hline
\end{tabular}




\section{Sexually transmitted diseases}

Many participants had never heard of STDs (45.5\%) (Table 4). The top symptoms of a STD agreed upon by the participants were: unusual discharge (22.9) and pain during urination $(16.9 \%)$ indicating some knowledge of the symptoms.

Table 4. Knowledge of sexually transmitted infections $(\mathrm{n}=79)$

\begin{tabular}{ccc}
\hline Topic & $\begin{array}{c}\text { Frequency } \\
(\mathbf{n}=\mathbf{7 9})\end{array}$ & $\begin{array}{c}\text { Percentage } \\
\mathbf{( \% )}\end{array}$ \\
\hline Heard of sexual & & \\
infections & & \\
Yes & & \\
& 42 & 54.5 \\
No & 35 & 45.5 \\
What are symptoms? & \\
& 4 & 4.8 \\
No symptoms & 5 & 6.0 \\
Genital warts & 0 & 0.0 \\
Spotting & 5 & 6.0 \\
Headache & 10 & 12.0 \\
Rash/Inflammation & 19 & 22.9 \\
Unusual discharge & 2 & 2.4 \\
Bloating & 14 & 16.9 \\
Pain during urination & 2 & 2.4 \\
Ulcers/sores in genital & & \\
area & & 26.5 \\
Vomiting & 22 & \\
\hline
\end{tabular}

\section{Perceptions and opinions of sexual practice}

Most participants thought that a girl's parents should be informed when acquiring contraceptives if she is younger than 16 (Table 5). Many knew that having sex with a girl younger than 16 was against the law (44.9\%). However, most participants $(70.5 \%)$ knew that the statement 'a girl cannot become pregnant the first time she has sex' was false. Participants were unsure about whether condoms always prevented sexually acquired infections (39.0\%).
Some participants agreed with the statement that the contraceptive pill prevents pregnancy $(57.7 \%)$.

The last section of the questionnaire investigated the personal opinions and preferences of the participants' sexual practice. A belief of being in love before having sexual intercourse prevailed (64.6\%), while strong disagreement was expressed with having a 'one night stand' (68.4\%). Participants agreed that sex is harder to refuse after having done it once $(46.8 \%)$ and that most of their close friends have had sexual intercourse $(50.6 \%)$. 
Table 5. Perceptions and opinions of sexual practice $(n=79)$

\begin{tabular}{|c|c|c|c|}
\hline \multirow[t]{2}{*}{ Opinion } & \multicolumn{3}{|c|}{ Frequency } \\
\hline & True & False & Don't know \\
\hline $\begin{array}{l}\text { If a girl is under } 16 \text { and asks for contraceptives } \\
\text { pill, the girls doctor must tell her parents }\end{array}$ & 39 & 25 & 15 \\
\hline $\begin{array}{l}\text { It is against the law to have sex with a girl who } \\
\text { is under } 16\end{array}$ & 35 & 25 & 18 \\
\hline $\begin{array}{l}\text { A girl cannot become pregnant the first time she } \\
\text { has sex }\end{array}$ & 7 & 55 & 16 \\
\hline $\begin{array}{l}\text { Condoms always prevent sexually acquired } \\
\text { infections }\end{array}$ & 37 & 10 & 30 \\
\hline \multirow{2}{*}{$\begin{array}{l}\text { The contraceptives pill always prevent against } \\
\text { pregnancy }\end{array}$} & 45 & 11 & 22 \\
\hline & Agree & Neutral & Disagree \\
\hline $\begin{array}{l}\text { You should be in love before you have sexual } \\
\text { intercourse }\end{array}$ & 51 & 18 & 10 \\
\hline $\begin{array}{l}\text { Once you had sex it is harder to say 'no' next } \\
\text { time }\end{array}$ & 37 & 26 & 16 \\
\hline I consider 'one night stands' to be ok & 7 & 18 & 54 \\
\hline $\begin{array}{l}\text { Most of my close friends have had sexual } \\
\text { intercourse }\end{array}$ & 40 & 14 & 25 \\
\hline
\end{tabular}

\section{Relationships between variables}

The $\mathrm{P}$ values obtained in the hypothesis testing is shown in Table 6. Five relationships were significant. 1) Significantly more males $(80 \%)$ reported that they had heard about STDs than females. 2) About $80.0 \%$ of learners who indicated that they had heard about SDT had parents who were unemployed. 3)More of those participants who were sexually inactive $(74 \%)$ tended to not have heard about STDs (4) Participants who reported that they had received information from a teacher (as compared to from a mother), also reported that they they were not sexually active (83\%). (5) However, $71 \%$ of those whose source of information was the teacher, did not use condoms. 
Table 6: Relationships between demographics, elements of knowledge about STDs and sexual practice

\begin{tabular}{|c|c|c|c|c|c|c|}
\hline $\begin{array}{l}\text { Sexual practice } \\
\text { and knowledge }\end{array}$ & Gender & Residence & $\begin{array}{c}\text { Parent's } \\
\text { employment }\end{array}$ & Knowledge & $\begin{array}{c}\text { Source of } \\
\text { knowledge }\end{array}$ & $\begin{array}{l}\text { Satisfied } \\
\text { with info }\end{array}$ \\
\hline Sexually active & 0.285 & 0.852 & 0.521 & $0.008 *$ & $0.013 *$ & 0.741 \\
\hline Contraceptive use & 0.818 & 0.382 & 0.129 & 0.938 & $0.044 *$ & 0.895 \\
\hline $\begin{array}{l}\text { Speaking about } \\
\text { condom use }\end{array}$ & 0.491 & 0.929 & 0.483 & 0.125 & 0.245 & 0.845 \\
\hline Knowledge of STIs & $0.043 *$ & 0.212 & $0.042 *$ & & 0.088 & 0.520 \\
\hline
\end{tabular}

*Significant at an alpha level of 0.05

\section{Discussion}

This study reports baseline data collected before implementation of the Stepping Stones health prevention programme in a rural school in North-west Province, South Africa. The students selected to call the programme at this school 'Stepping into the Right Future'. We highlight the vulnerability and risks adolescents face in low resource environments. The young learners that participated did not have sufficient knowledge regarding sexual practice but were already engaging in risky sexual behaviours. The sample was skewed towards females $(78.5 \%)$ which is not representative of the North-West population (females $=49.3 \%$ ). The young age group sampled in our study has consequences for the interpretation of our results with grade 8 students, comprising almost half of the sample. Whilst much younger than the sexually vulnerable age, these learners reported sexual activity that placed them at risk of teenage pregnancy and STDs.

Although only 21 learners reported being sexually active, 42 learners reported some sort of sexual activity, and 41 learners reported having current sex partners. This means that participants may not have been totally honest in their answers. As the question about the number of sex partners were later in the questionnaire, it may mean that they relaxed as they progressed and were more open in responding authentically. Alternatively, they perhaps understood by the question dating partners, and not necessarily sexual partners.

The young reported age of sexual debut in this study, is congruent with other South African studies assessing female debut ${ }^{1,3}$, especially as girls tend to have their sexual debut at a later age than boys ${ }^{14}$.
None of the learners had children, although two previous pregnancies were reported. This is lower than the reported $5.4 \%$ of 14 to 19 -year old girls in the General Household Survey $2013^{3}$. The pregnancy rate in the current study is probably an underestimate. Learners were possibly reluctant to disclose previous pregnancies, especially if they had an abortion and/or they mistrusted the true anonymity of the questionnaires.

A major aspect of concern is the low level of contraceptive use, which is $100 \%$ of the teenagers that reported being sexually active. This proportion is far below the average of $52.2 \%$ reported in the Reproductive Health Research Unit 2003 study $^{15}$, and is much less than international levels of teenage contraceptive use in teenagers, measured at $79 \%{ }^{16}$.

The relatively high level of sexual activity is surprising as most of the learners reported being Christian, a religion that promotes abstinence from sex until marriage. The reason for the low uptake of contraceptives may be explained by this fact. Participants, in light of their religious norms, probably planned to abstain from sex until marriage and therefore did not take preventative measures, such as using condoms. A Kenyan study also carried out in a mixed day secondary school, supported the fact that low uptake of contraceptives can be due to religious beliefs, practices, and involvement in a faith community. ${ }^{17}$

Of those who did take preventative measures, the most popular means of contraceptive was condoms, which is in agreement with national and international literature ${ }^{16,18}$. However, many participants had difficulty talking about condom use with their partner. This may be another rea-

African Health Sciences Vol 20 Issue 1, March, 2020 
son resulting in the large number of sexually active participants not using condoms or contraceptives. Condom use is likely to decrease as the age gap between partners increases and it is known that in this community young girls often have older sexual partners. Internationally, condom use was also negatively associated with younger sexual debut and an older partner, as in this study ${ }^{19}$.

Most of the learners stated that 'being in love' was an acceptable reason for engaging in sexual activity. The notion of being 'in love' coupled with pressure from older male partners may drive young women who are not psychologically ready towards sexual intercourse ${ }^{20}$. Contrary to previous studies, most of the sexually active participants did not regret having sex which is a worrying factor. The cause for the group who regretted having sex, may have been the cases of forced sex and gender inequalities. Gender inequality, as in this study, is a large contributing factor towards unwanted pregnancy and the spread of STDs ${ }^{5}$. A contradictory finding, is that half of the sexually active male participants had sex after one meeting, whilst girls opted for getting to know the sexual partner for a few months and being in a committed relationship. Older males partnering with multiple younger females are associated with high HIV transmission rates and teenage pregnancies in South Africa ${ }^{15}$. Prevention interventions need to focus on behavioural problems and perceptions that promote the spread of HIV amongst young women. The lack of knowledge about sexually transmitted diseases and teenage pregnancy in the current study is of concern. Whilst knowledge of contraceptive use is high, according to the Department of Education ${ }^{15}$, other areas of prevention were insufficient. Many participants were unsure about whether a condom always prevented STDs and most participants were unaware that engaging in sexual behaviour before the age of 16 was illegal. The lack of knowledge in most questionnaire items demonstrates the immaturity of the sample and illuminates the high risks of teenage pregnancy and sexually transmitted disease amongst adolescents.

This level of sexual activity in this study is probably an underestimate, as almost half of the sample were in the lowest grade (Grade 8), but more of the relatively older participants (in terms of age) reported to be sexually active. Nevertheless, South African Grade 8 learners are engaging in risky sexual behaviour and require sexual and reproduction education programmes tailored to the age group $^{21}$. Adolescents require sexual negotiation sklls, improved sexual decision making and the ability to critically examine social scripts and peer pressures ${ }^{10,16}$.

Many participants received sexual and reproductive education information from parents. The risk of teenage pregnancy is decreased if the mother and/or both parents live at home ${ }^{22}$. Parents need to initiate intimate conversations with adolescents whilst sexual development is taking place 22 .

The primary source of information was from school. Although learners who obtained information from teachers, tended to be significantly less sexually active, this group, was when sexually active significantly less prone to use a condom. Whilst traditional school-based education programmes provide awareness and knowledge, they have not been successful in changing adolescent sexual behaviour $^{21}$. Group settings may be the most practical method of education delivery where conversations would reinforce what is learnt in the group settings and allow adolescents to evaluate situations with peers. Media delivered via television and social media may be effective educational tools since they are widely available via cellphone and interactive. Such tools may overcome logistical difficulties such as transport to and from sessions and having to provide refreshments ${ }^{22}$.

In terms of sexual knowledge, males were more knowledgeable, which is an international trend. For example, in Democratic Republic of Congo $54.3 \%$ of males have heard about HIV as compared to $45,7 \%$ of girls. ${ }^{23}$ Also, in Germany adolescent males had a better knowledge than females about HIV and STIs. ${ }^{24}$ As expected those who were not sexually active also tended not to have heard of STIs. Those who are curious about sex, and see it as a normal transition to adulthood, tend to be more open to information ${ }^{25}$

Those with unemployed parents, however, have heard more often of STIs than those with employed parents. We could not explain this finding, neither could we find literature about this relationship. This is an example, where a qualitative elements in the research, such as interviews would enhance the understanding of findings. The relationship between whether learners got sexual information from a teacher or the mother, and whether they were sexually active and/or have heard about STIs, 
was ambiguous. Those with the teacher as source tended to be less sexually active, however, when active, tended to not used condoms. These results confirm the importance of educating teachers and including comprehensive sexual educationin school-based programmes ${ }^{26,27}$ following best practice guidelines ${ }^{28}$ but also to include a variety of stakeholders, including both parents and teachers ${ }^{29}$.

The study was limited by the over-representation of females in the sample. Although the methodology was suitable for baseline data collection, the closed-ended questioning style yielded superficial data. For example, the reasons for not regretting having sex, stay unclear. Another limitation is, that the questionnaire was paper-based and all participants received all the questions. Follow up questions about sexual activity could therefore also be answered by those who reported that they were not sexually active as explained in the last two sentences under the section 'Age at sexual debut and sexual activity'. Importantly, the survey did not distinguisch between ever use, current use and never use, of contraceptives. Finally, the survey investigated only current and not lifetime sexual activity.

The awareness created by this study would help practitioners provide appropriate interventions in an age group that are increasingly sexually active and engaging in high risk behaviours.

\section{Conclusion}

The results from this study are consistent compared to age- and gender-related sexual activities and knowledge reported for adolescents elsewhere in South Africa, but with less favourable level of use of condoms. The study reports the baseline data about the sexual practices and knowledge of learners attending a secondary school in North-West, South Africa. Participants were sexually active, inconsistently used contraceptives, had insufficient knowledge of sex and had skewed perceptions of sexual behaviour. A long-term, peer-to-peer programme, such as the Stepping Stones programme could benefit the school and community ${ }^{11}$. Social media may complement sessions and link parents to knowledge delivery. Gender equality and sexual decision making skills are needed for sustainable prevention of HIV and teenage pregnancy.

\section{Acknowledgements}

Thank you to the principal and involved teachers of
Mmalankala Technical School, the community worker, Mrs Joyce Kwena Mabasa, research assistant for data collection, Mr Ndunge Tulane for capuring of data; Me Amé Harris, research assistant for data analysis and writing of the first draft. Dr Cheryl Tosh for editing the article and to the participants and their parents. Financial support was received from the Research Support Department, Faculty of Health Care Sciences, University of Pretoria.

\section{References}

1. Berry L, Hall K. Teenage pregnancy. Children's Institute: University of Cape Town; 2009.

2. Willan S. A review of teenage pregnancy in South Africa-Experiences of schooling, and knowledge and access to sexual \& reproductive health services. Partners in Sexual Health. 2013:1-63.

3. Statistics SA. General Household Survey. South Africa: Statistics South Africa; 2015.

4. Statistics SA. Mid-year population estimates: 2015. Statistics South Africa; 2015. Contract No.: P0302.

5. Mchunu G, Peltzer K, Tutshana B, Seutlwadi L. Adolescent pregnancy and associated factors in South African youth PMCID: PMC3598281. Afr Health Sci. 2012;12(4):426-34.

6. UNAIDS. Global AIDS Update-2016. UN Joint Programme on HIV/AIDS; 2016.

7. Peltzer K. Early sexual debut and associated factors among in-school adolescents in eight African countries. Acta Paediatrica (Oslo, Norway : 1992). 2010;99(8):1242-7. 8. Idele P, Gillespie A, Porth T, Suzuki C, Mahy M, Kasedde S, et al. Epidemiology of HIV and AIDS among adolescents: current status, inequities, and data gaps. JAIDS J Acquired Immune Deficiency Syndromes. 2014;66:S144-S53.

9. Shishana O, Rehle T, Simbayi L, Zuma K, Jooste S, Zungu N, et al. South African National HIV Prevalence, Incidence and Behaviour Survey, 2012. Cape Town: HSRC Press; 2014.

10. Tumwine JK. Sexuality and other issues in Africa and beyond. Afr Health Sci. 2018;18(2):1-3.

11. Ardington C, Menendez A, Mutevedzi T. Early childbearing, human capital development and mortality risk. A Southern Africa Labour and Development Research Unit Working Paper Number 56. Cape Town: SALDRU, University of Cape Town; 2011.

12. Scott-Sheldon L, Walstrom P, Harrison A, Kalichman $\mathrm{S}$, Carey M. Sexual risk reduction interventions for HIV prevention among South AfricanYouth: a meta-analytic review. Current HIV Research. 2013;11(7):549-58. 
13. Skevington SM, Sovetkina EC, Gillison FB. A systematic review to quantitatively evaluate 'Stepping Stones': a participatory community-based HIV/AIDS prevention intervention doi: 10.1007/s10461-012-0327-6. AIDS Behav. 2013;17(3):1025-39.

14. Pettifor A, O'Brien K, MacPhail C, Miller WC, Rees H. Early coital debut and associated HIV risk factors among young women and men in South Africa. International Perspectives on Sexual and Reproductive Health. 2009:82-90.

15. Panday S, Makiwane M, Ranchod C, Letsoala T. Teenage pregnancy in South Africa: with a specific focus on school-going learners. Pretoria, South Africa: Department of Basic Education, Human Sciences Research Council and UNICEF 2009.

16. Martinez G, Abma JC. Sexual activity, contraceptive use, and childbearing of teenagers aged 15-19 in the United States. U.S Department of Health and Human Services; 2015. Contract No.: 209.

17. Capomolla S, Ceresa M, Civardi A, Lupo A, Ventura A, Scabini M, et al. Home exercise therapy in chronic congestive heart failure: observational study of factors affecting adherence to the program. [Training fisico domiciliare nello scompenso cardiaco cronico: studio osservazionale sui fattori condizionanti l'aderenza al programma.] PMID:12506511. Ital Heart J. 2002;3(11):1098105.

18. Esho T, Datta A, Muniu S. Sexuality experiences of secondary school students in Nakuru, Kenya: a cross-sectional study https://dx.doi.org/10.4314/ahs.v18i2.3. Afr Health Sci. 2018;18(2):209-17.

19. Dietrich J, Sikkema K, Otwombe KN, Sanchez A, Nkala B, de Bruyn G, et al. Multiple levels of influence in predicting sexual activity and condom use among adolescents in Soweto, Johannesburg, South Africa. J HIV AIDS Soc Serv. 2013;12(3-4):404-23.

20. Akintola O, Ngubane L, Makhaba L. 'I did it for him, not for me': An exploratory study of factors influencing sexual debut among female university students in Durban, South Africa. J Health Psychol. 2012;17(1):143-53.

21. Bogart LM, Skinner D, Thurston IB, Toefy Y, Klein DJ, $\mathrm{Hu} \mathrm{CH}$, et al. Let's talk!, A South African worksitebased HIV prevention parenting program. I Adolesc Health. 2013;53(5):602-8.

22. Gibbs A, Jewkes R, Mbatha N, Washington L, Willan S. Jobs, food, taxis and journals: complexities of implementing Stepping Stones and Creating Futures in urban informal settlements in South Africa. Afr J AIDS Res. 2014;13(2):161-7.

23. Mudingayi A, Lutala P, Mupenda B. HIV knowledge and sexual risk behavior among street adolescents in rehabilitation centres in Kinshasa; DRC: gender differences. Pan Afr Med J. 2011;10.

24. von Rosen F, von Rosen A, Müller-Riemenschneider F, Damberg I, Tinnemann P. STI knowledge in Berlin adolescents. Int J Environ Res Public Health. 2018;15(1):110.

25. Ott MA, Pfeiffer EJ. “That's Nasty” to Curiosity: Early Adolescent Cognitions about Sexual Abstinence. I Adolesc Health. 2009;44(6):575-81.

26. United Nations Educational SaCOU. Comprehensive sexuality education: challenges and opportunities of scaling-up. Paris: UNESCO; 2012.

27. United Nations Educational, Scientific and Cultural Organization (UNESCO). 2015. Comprehensive sexuality education in teacher training in Eastern and Southern Africa. Geneva: UNESCO.

28. Pound P, Denford S, Shucksmith J, Tanton C, Johnson AM, Owen J, et al. What is best practice in sex and relationship education? A synthesis of evidence, including stakeholders' views. BMJ Open. 2017;7(5):e014791.

29. United Nations Population Fund (UNPF). 2015. Incorporating comprehensive sexuality education within higher and basic education institutions in KwaZulu-Natal. Pretoria, South Africa: UNPF. 